\title{
NON-INVASIVE PREDICTORS OF PORTAL HYPERTENSION IN PATIENTS WITH HEPATITIS C VIRUS RELATED HEPATOCELLULAR CARCINOMA
}

\author{
By \\ ZAKARIA MOHRAN ${ }^{1}$, MOHAMED SAKR ${ }^{1}$, EMAN BARAKAT ${ }^{1}$, AHMED ELBAZ $^{1 *}$, \\ MOHAMED ABD AL-HAMID ${ }^{1}$, MOHAMED ABOU-ELMAATY ${ }^{2}$
}

Department of Tropical Medicine, Gastroenterology and Hepatology ${ }^{1}$ and Department of Radiology ${ }^{2}$, Faculty of Medicine, Ain Shams University, Cairo11566, Egypt

(*Correspondence email: ahmedelbaz75@gmail.com)

\begin{abstract}
The reference standard for portal venous pressure measurement which is clinically important for estimating the feasibility of resection of hepatocellular carcinoma is the hepatic venous pressure gradient, which is invasive and expensive. The present study evaluated the noninvasive parameters for assessment of portal hypertension in Child A patients with hepatocellular carcinoma on top of hepatitis $\mathrm{C}$ virus.

A total of 112 patients were subjected to clinical assessment, biochemical assay, ultrasonographic Doppler study, triphasic spiral abdominal computed tomography, upper gastrointestinal endoscopy and hepatic venous pressure gradient measurement. According to hepatic venous pressure gradient measurement, they were classified into groups: GI: 58 patients with hepatic venous pressure gradient $<10 \mathrm{mmHg}$ and GII: 54 patients with hepatic venous pressure gradient $\geq 10 \mathrm{mmHg}$. Significant variables in univariate analysis were included in a multivariate analysis to establish a model for prediction of clinically significant portal hypertension.

Results showed that portal vein diameter $\geq 1.3 \mathrm{~cm}$, mono or biphasic pattern of flow in hepatic veins and Giannini index $\leq 909$ were independent risk factors for the clinically significant portal hypertension as indicated by HVPG $\geq 10 \mathrm{mmHg}$. A model with highest likelihood ratio and good fitness was created. This prediction model was displayed by the receiver operating characteristic curve and under the curve area was 0.969 (0.938-1).
\end{abstract}

Keywords Hepatocellular carcinoma, Hepatic venous pressure gradient, Portal vein diameter, Hepatic vein, Giannini index

\section{Introduction}

In the setting of cirrhosis, measurement of portal venous $(\mathrm{PV})$ pressure is clinically important when diagnosing portal hypertension, estimating the likelihood of variceal bleeding, monitoring the progress of therapy (De Franchis et al, 2008) and also assesses feasibility of resection in patients with hepatocellular carcinoma (HCC) (Parikh, 2009). Normal bilirubin concentration and hepatic vein pressure gradient (HVPG) of less than $10 \mathrm{mmHg}$ in Child A cirrhotic patients are the best predictors of excellent outcome after resection and are associated with almost no risk of postoperative liver failure with 70\% 5-year survival (Llovet et al, 2008). The reference standard for measurement of portal venous pressure is HVPG calculated by subtracting the free hepatic venous pressure from the wedged hepatic venous pres- sure. Unfortunately, calculation of HVPG is invasive and expensive, and it cannot be used to monitor therapy. An accurate noninvasive technique that could be used to measure portal venous pressure would represent a major advance in the diagnosis and management of portal hypertension (Parikh, 2009). Several clinical, biochemical, and imaging parameters alone or together have good predictive power for non-invasive assessment of portal hypertension. Some parameters have been found to have a high specificity and sensitivity for the diagnosis of cirrhotic portal hypertension with ultrasound colour duplex Doppler examination such as coarse shrunken liver, dilated portal vein (diameter $>13 \mathrm{~mm}$ ), size of spleen, splenic vein (SV) diameter and ascites (Cottone et al, 1986), lack or reduced respiratory variations of splenic and superior mesenteric 
vein diameter (Bolondi et al, 1982), reversal of portal blood flow, reduced portal vein velocity (Zoli et al, 1993), portal-systemic collateral circulation (van Leeuwen, 1990), altered hepatic venous Doppler pattern (Baik et al, 2006), increased intraparenchymal hepatic and splenic artery impedance (Sacerdoti et al, 1991; Bolognesi et al, 2001), increased intraparenchymal renal artery impedance (Berzigotti et al, 2006), increased congestion index of portal vein (Moriyasu et $a l, 1986)$ and reduced mesenteric artery impedance (Taourel et al, 1998).

The present study evaluated clinical, biochemical and ultrasonographic Doppler parameters with good predictive power for non-invasive assessment of portal hypertension in Child A patients with HCC on top of $\mathrm{HCV}$ related chronic liver disease so that to be excluded from hepatic resection list.

\section{Patients and Methods}

The present study was cross-sectional comparative conducted on 112 patients with HCC admitted from November 2010 to August 2013. The study was approved by the medical ethics committee of Ain Shams University and conducted in accordance with the principles of the declaration of Helsinki. All patients provided written informed consent before enrollment. Inclusion criteria were patients with HCV related chronic liver disease, Child class (A) with HCC which was diagnosed according to the following suggested alghorism shown in fig. 1 for the diagnostic strategy after detection of hepatic nodule by ultrasound (Bruix and Sherman, 2005); absence of portal, splenic, hepatic vein thrombosis, any vascular invasions or arterio-venous fistula; absence of previously sclerosis or band ligation of oesophageal varices, transjugular intrahepatic portosystemic stent shunt, or surgery for portal hypertension; absence of drug intake for primary prophylaxis of variceal bleeding or previously any intervention for HCC. Study Design and procedures
All patients were subjected to complete history taking, thorough clinical examination, laboratory investigations including complete blood count, liver profile, renal profile, hepatitis $\mathrm{C}$ virus antibody using third generation ELISA test and serum alphafetoprotein. Abdominal color Doppler ultrasonographic study by an ultrasound machine (Logic 9, General Electric, medical systems, Milwaukee, USA) was used, after 6 hours fasting, to assess the liver (size and echogenicity), portal vein (patency, diameter, portal vein cross sectional area, mean portal vein flow velocity and direction of flow), hepatic venous Doppler pattern, hepatic artery resistance index, spleen size, splenic vein (patency, diameter, splenic vein cross sectional area, mean splenic vein flow velocity), splenic artery resistance index, intraparenchymal renal artery resistive index (RARI), status of ascites and portosystemic collaterals. The portal vein cross sectional area (PV CSA) $\left(\mathrm{cm}^{2}\right)$ was obtained assuming portal vein to be circular in cross section and calculated by the computer software of the machine up to $0.99 \mathrm{~cm}^{2}$ in normal subjects (Moriyasu et al, 1986; Pozniak, 2002). The average mean portal vein flow velocity (mean PVV) $(\mathrm{cm} / \mathrm{sec})$ is above $19 \mathrm{~cm} / \mathrm{sec}$ in normal subjects (Ozaki et al, 1988). Direction of flow was assessed so that if the flow is towards the transducer, it displays red color (hepatopetal), but if the flow is away from the transducer, it displays blue color (hepatofugal). In cases with both red and blue colors, the flow is bi-directional. The splenic vein cross sectional area (SV CSA) $\left(\mathrm{cm}^{2}\right)$ and mean splenic vein flow velocity (mean SVV) $(\mathrm{cm} / \mathrm{sec})$ were calculated in the same way described with the portal vein. The normal SV CSA is up to $0.5 \mathrm{~cm}^{2}$ and the average mean SVV is $19.9 \pm 4.6 \mathrm{~cm} / \mathrm{sec}$ in normal subjects (El Zeiny et al, 2002). Hepatic artery resistance index (HARI) was measured in the intrahepatic main branches. The resistance index (RI) was calculated 
over one cardiac cycle from the formula: RI $=$ (systolic velocity-end diastolic velocity $) /$ systolic velocity (this was calculated by machine software). Average value was 0.68 in normal one (Schneider et al, 1999). Splenic artery resistance index (SARI) was measured intra-parenchymally, near to the hilum. It was calculated like HARI, cutoff value is 0.60 in normal subjects (Sacerdoti et al, 1991). The reported values of the Doppler parameters were obtained by taking the average value of 3 consecutive measurements. Also the following indices were calculated; congestion index (CI) $(\mathrm{cm} / \mathrm{sec}-1)$ which was calculated for portal and splenic veins as: $\mathrm{CI}$ $=\mathrm{CSA} /$ mean velocity, The average PV CI in normal subjects is up to $0.07 \mathrm{~cm} / \mathrm{sec}-1$ and the average SV CI is up to $0.04 \mathrm{~cm} / \mathrm{sec}-1$ (Pozniak, 2002; El Zeiny et al, 2002). Modified liver vascular index (MLVI) $(\mathrm{cm} / \mathrm{sec})$ was calculated as: portal flow velocity/ hepatic artery RI (Piscaglia et al, 2001). Portal hypertension index (PH index) (m/sec-1) was calculated as: [(hepatic artery $\mathrm{RI} \times 0.69)$ $\times($ splenic artery RI $\times 0.87)] /$ portal vein mean velocity (Piscaglia et al, 2001). Portosystemic collaterals e.g. left gastric vein, paraumbilical vein, porta hepatis collaterals, lienorenal collaterals, splenic hilar collaterals and gastrorenal collaterals were also examined. Hepatic venous Doppler pattern was assessed either monophasic, biphasic or diphasic. Platelet count/spleen diameter ratio was calculated in millimeters by Giannini index (Giannini et al, 2003). Upper gastrointestinal (GIT) endoscopy Pentax EG-3440 videoscope system was used to evaluate the presence and degree of varices in addition to any relevant upper GIT lesions. Triphasic spiral abdominal computed tomography (CT) was done to diagnose HCC by typical vascular pattern and to assess tumor site, size, number and extension. HVPG was measured with the patients under local anesthesia, a venous introducer was placed in the right internal jugular vein and a 5 French catheter with cobra head configuration was advanced under fluoroscopic control into the main right hepatic vein. Using an invasive monitor, pressure was measured while tip of catheter was floating in the middle of the hepatic vein (free hepatic venous pressure (FHVP). The catheter is then pushed down in the hepatic vein until it cannot be advanced further, which results in a complete obstruction of flow (position of catheter was confirmed by using contrast material); the pressure recorded in the occluded position (using invasive monitor) is the wedged hepatic venous pressure (WHVP). HVPG was calculated by subtracting the FHVP from the WHVP. The HVPG is the difference between the portal vein and the inferior vena cava pressures (IVCP) and represents the real perfusion pressure within the portal and hepatic circulations. Normal HVPG is about 1-5 mmHg. When HVPG increases above 10-12 $\mathrm{mmHg}$, a number of life-threatening complications can occur (Parikh, 2009).

Statistical analysis: Data were analyzed using SPSS for Windows (version 19.0). Continuous variables were expressed in term of mean and standard deviation (except for alpha-fetoprotein which was expressed in term of median and inter-quartile range) and ordinal and nominal categorical data were described as number and percentages (frequency). Chi-square test with Yates correction and Fisher-Exact were used to test association between two categorical variables. Student-t-test was used to test means' differences between groups (except for alpha-fetoprotein where Mann Whitney test was used). Variables were significant at $\mathrm{P}<0.05$. Logistic regression analysis was performed to identify variables independently associated with presence of clinically significant portal hypertension and established model for prediction significant portal hypertension in patients. As all significant variables in univariate analysis could not be included in the same regression model, different models 
were generated. The best one was judged by likelihood ratio, significance of introduced predictors, odds ratio and confidence interval together with fitness and productivity of the model.

\section{Results}

As to HVPG measurement, patients were classified into two groups: GI included 58 patients $(51.8 \%)$ with HVPG less than 10 mmHg. Mean HVPG was 5.5+/-1.8 $\mathrm{mmHg}$. GII included 54 patients $(48.2 \%)$ with HVPG equal to or more than $10 \mathrm{mmHg}$. Mean HVPG was $15.2+/-2.3 \mathrm{mmHg}$. Demographic profile and laboratory parameters were similar in both groups except a lower statistical significant difference in GII in comparison to GI regarding hemoglobin level, white blood cells and platelet counts. Patients in GII had statistically higher values of creatinine and alpha fetoprotein in comparison to GI. All patients had coarse echogenicity of liver with no detectable ascites on abdominal ultrasonography. Most of them had single hepatic focal lesion (HFL) in the right lobe of the liver. Patients in GII had larger spleen, more frequent to have collaterals and their Giannini index was significantly lower than patients in GI. As to upper GIT endoscopy findings, esophageal varices, fundal varices and portal hypertensive gastropathy (PHG) were significantly common in GII than GI (Tab. 1). All patients had patent portal vein with hepatopedal direction of flow and patent splenic vein. Doppler parameters were higher in GII compared to GI with a highly significant difference (Tab. 2).

Significant variables in univariate analysis were included into a binary logistic regression analysis stepwise method. The best predictive model gave the highest likelihood ratio; the relatively high predictivity meanwhile showed a good fitting using Hosmer \& Lemshow Goodness of fit test. Portal vein diameter more than or equal to $1.3 \mathrm{~cm}$, mono or biphasic pattern of flow in hepatic veins and Giannini index below or equal to 909 were found to be independent risk factors for presence of clinically significant portal hypertension as indicated by HVPG more than 10 in this study (Tab. 3). The performance of this prediction model is displayed by the receiver operating characteristic (ROC) curve. The area under the curve (AUC) was 0.969 (0.938-1), showed that this model gave a good discrimination between patients with HVPG more than 10 and those with lower HVPG (Fig. 2). A total of 37 patients fulfilled all parameters included in model (Predicted probability $=.98260$ ); only one had HVPG less than 10 and 20 had none of model parameters positives (Predicted probability $=.00238$ ); all had HPVG less than 10, an example of the general result that if $\log [\mathrm{P} \quad(\mathrm{Y}=1) / \mathrm{P}(\mathrm{Y}=0)]=\mathrm{b}_{0}+$ $\mathrm{b}_{1} \mathrm{X}_{1}+\ldots+\mathrm{b}_{\mathrm{p}} \mathrm{X}_{\mathrm{p}}$ then "P $(\mathrm{Y}=1)=\exp \left(\mathrm{b}_{0}+\right.$ $\left.\left.b_{1} X_{1}+. .+b_{p} X_{p}\right)\right]$ " or "P $(Y=1)=1 /\{1+\operatorname{esp}[$ - $\left.\left(\mathrm{b}_{0}+\mathrm{b}_{1} \mathrm{X}_{1}+. .+\mathrm{b}_{\mathrm{p}} \mathrm{X}_{\mathrm{p}}\right)\right]$ \}" So, P (Predicted probability of High HVPG) $=1 / 1+\exp \{-$ (constant (-6.039) +4.51 (when PV diameter 1.3 or more) +3.55 (when mono- or biphasic HV Doppler pattern) + 2.01(when PLT/ spleen ratio 909 or less) $\}$

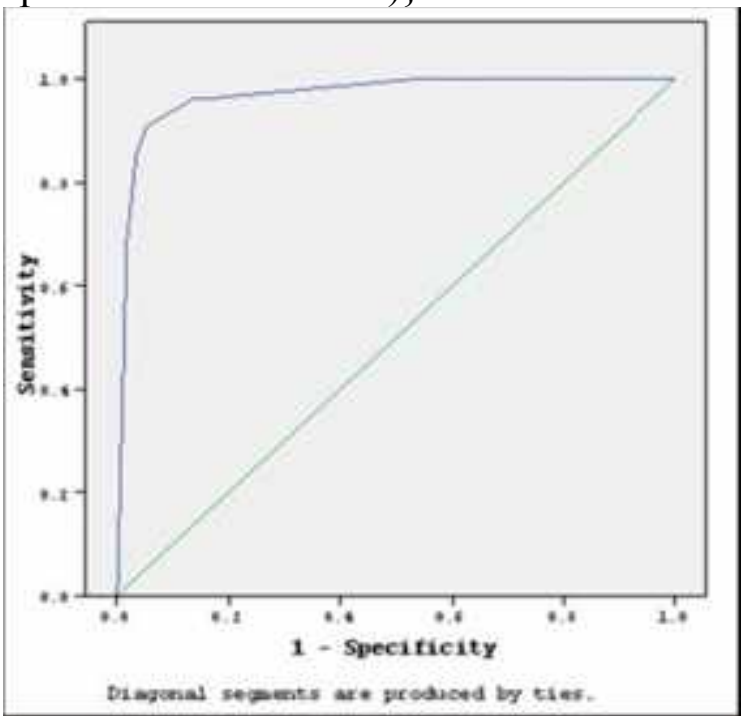

Fig. 1: ROC curve displaying discrimination ability of predictors model for HVPG (AUC 0.969 - 95\% CI 0.938-1.0). 
ROC receiver operator characteristic, AUC area under curve.

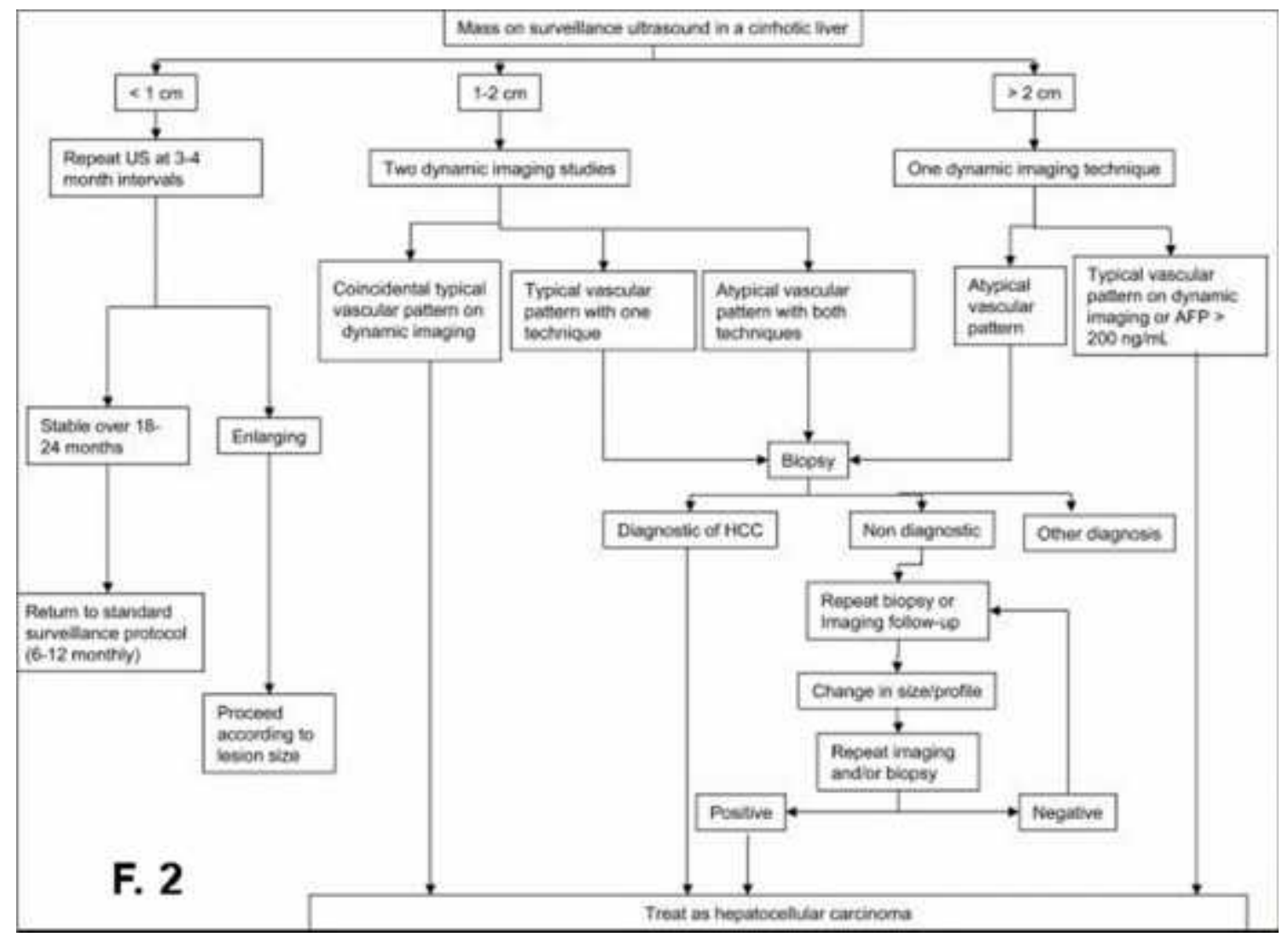

Fig. 2: Algorithm to investigate nodule in ultrasound during screening or surveillance (Bruix and Sherman, 2005).

Table 1: Characteristics of study population

\begin{tabular}{|c|c|c|c|}
\hline Variable & GI $(\mathrm{N}=58)$ & GII $(\mathrm{N}=54)$ & $P$ value \\
\hline Age (Years) & $55.97 \pm 7.284$ & $55.96 \pm 5.956$ & 0.998 \\
\hline Sex (Male/Female) & $49 / 9$ & $41 / 13$ & 0.255 \\
\hline Hemoglobin $(\mathrm{gm} / \mathrm{dl})$ & $13.410 \pm 1.0327$ & $12.902 \pm 1.2369$ & 0.020 \\
\hline White blood cells $\left(10^{9} / \mathrm{L}\right)$ & $5.888 \pm 1.9256$ & $4.739 \pm 1.4060$ & $<0.001$ \\
\hline Platelets $\left(10^{9} / \mathrm{L}\right)$ & $154.52 \pm 46.678$ & $96.09 \pm 37.913$ & $<0.001$ \\
\hline Alanine transaminase $(\mathrm{U} / \mathrm{L})$ & $62.24 \pm 25.461$ & $55.50 \pm 18.137$ & 0.108 \\
\hline Creatinine $(\mathrm{mo} / \mathrm{dl})$ & $0.856 \pm 0.1456$ & $0.999 \pm 0.1708$ & $<0.001$ \\
\hline Alpha fetoprotein $(\mathrm{ng} / \mathrm{dl})$ & $44.50(\mathrm{IQR}=14.3-188.58$ & $102(\mathrm{IOR}=30.5-1004.5$ & 0.005 \\
\hline Liver size (shrunken/average/enlarged) & $2 / 40 / 16$ & $0 / 45 / 9$ & 0.086 \\
\hline Collaterals & 1 & 27 & $<0.001$ \\
\hline Splenic diameter $(\mathrm{cm})$ & $13.48 \pm 1.78$ & $16.63 \pm 2.53$ & $<0.001$ \\
\hline No. of HFLs $(1 / 2 / 3)$ & $44 / 12 / 2$ & $45 / 8 / 1$ & 0.602 \\
\hline Site of HFLs (Right lobe/Left/Both) & $44 / 14 / 0$ & $46 / 5 / 3$ & 0.14 \\
\hline Size of largest HFL $(\mathrm{cm})$ & $4.866 \pm 1.77$ & $5.159 \pm 2.0481$ & 0.420 \\
\hline Oesophageal varices & $10(17.2 \%)$ & $54(100 \%)$ & $<0.001$ \\
\hline Fundal varices & $0(0 \%)$ & $13(24.1 \%)$ & $<0.001$ \\
\hline PHG & $7(12.1 \%)$ & $34(63 \%)$ & $<0.001$ \\
\hline Giannini index $(\mathrm{mm})$ & $1159.82 \pm 345.66$ & $611.89 \pm 305.04$ & $<0.001$ \\
\hline
\end{tabular}

Table 2: Independent factors predicting HVPG

\begin{tabular}{|l|c|c|c|c|}
\hline Variables & $\mathrm{B}^{\mathrm{a}}$ & $\mathrm{SE}^{\mathrm{b}}$ of $\mathrm{B}^{\mathrm{a}}$ & $\mathrm{P}$ value & $\mathrm{OR}^{\mathrm{c}}\left(95 \% \mathrm{CI}^{\mathrm{d}}\right)$ \\
\hline PV Diameter $\geq 1.3 \mathrm{~cm}$ & 4.51 & 0.88 & $<0.001$ & $90.9(15.9-518.2)$ \\
\hline Mono/Biphasic hepatic veins doppler pattern & 3.55 & 1.10 & 0.001 & $34.8(3.9-303.9)$ \\
\hline Giannini Index $\leq 909$ & 2.01 & 0.81 & 0.013 & $7.5(1.5-36.3)$ \\
\hline Constant & 6.039 & 1.345 & $<0.001$ & \\
\hline
\end{tabular}

${ }^{\mathrm{a}} \mathrm{B}=$ Regression Coefficient, ${ }^{\mathrm{b}} \mathrm{SE}=$ Standard Error, ${ }^{\mathrm{c}} \mathrm{OR}=$ Odds Ratio and ${ }^{\mathrm{d}} \mathrm{CI}=$ Confidence Interval. 
Table 3: Comparison between groups regarding Doppler parameters.

\begin{tabular}{|c|c|c|c|}
\hline Variable & $\mathrm{GI}(\mathrm{N}=58)$ & G II $(\mathrm{N}=54)$ & $P$ value \\
\hline PV diameter $(\mathrm{cm})$ & $1.033 \pm 0.1559$ & $1.559 \pm 0.2469$ & \multirow{17}{*}{$<0.001$} \\
\hline $\mathrm{PV} \operatorname{CSA}(\mathrm{cm} 2)$ & $1.124 \pm 0.2189$ & $1.997 \pm 0.5512$ & \\
\hline mean PVV $(\mathrm{cm} / \mathrm{sec})$ & $21.68 \pm 2.848$ & $12.69 \pm 2.360$ & \\
\hline PV CI $(\mathrm{cm} / \mathrm{sec}-1)$ & $0.06958 \pm 0.086437$ & $0.16984 \pm 0.078771$ & \\
\hline SV diameter $(\mathrm{cm})$ & $0.658 \pm 0.1003$ & $0.985 \pm 0.1951$ & \\
\hline SV CSA $(\mathrm{cm} 2)$ & $0.576 \pm 0.0927$ & $0.934 \pm 0.2529$ & \\
\hline mean SVV $(\mathrm{cm} / \mathrm{sec})$ & $19.22 \pm 2.120$ & $12.83 \pm 2.309$ & \\
\hline $\mathrm{SV}$ CI $(\mathrm{cm} / \mathrm{sec}-1)$ & $0.03048 \pm 0.007121$ & $0.07704 \pm 0.031416$ & \\
\hline HARI & $0.6409 \pm 0.04426$ & $0.7050 \pm 0.06737$ & \\
\hline SARI & $0.6267 \pm 0.03827$ & $0.6726 \pm 0.04020$ & \\
\hline RARI & $0.6164 \pm 0.04483$ & $0.6757 \pm 0.05236$ & \\
\hline MLVI $(\mathrm{cm} / \mathrm{sec})$ & $33.974 \pm 5.5116$ & $18.251 \pm 4.2253$ & \\
\hline PH index (m/sec- 1$)$ & $0.01138 \pm 0.002239$ & $0.02350 \pm 0.006442$ & \\
\hline \multicolumn{3}{|l|}{ Hepatic veins Doppler pattern } & \\
\hline Monophasic & $0(0 \%)$ & $14(25.9 \%)$ & \\
\hline Biphasic & $28(48.3 \%)$ & $37(68.5 \%)$ & \\
\hline Triphasic & $30(51.7 \%)$ & $3(5.6 \%)$ & \\
\hline
\end{tabular}

\section{Discussion}

In Egypt, there was a growing incidence of HCC (10-120/100,000), which represents the leading cause of death from all other cancer sites (El-Zayadi et al, 2010). Resection and transplantation achieve the best outcomes in well-selected candidates; 5-year survival of $60-80 \%$ (Llovet et al, 2012). The selection of optimal candidates for liver resection is usually based on the degree of portal hypertension (Llovet et al, 2008). The reference standard for measurement of portal venous pressure is the HVPG which is invasive and expensive (Parikh, 2009).

In the present study, both groups were age and sex matched without significant differences between them. Hemoglobin level, white blood cells and platelet counts showed significant lower differences in GII in comparison to GI agreed with others (Sharma et al, 2007; Qamar et al, 2008), also thrombocytopenia was correlated with clinically significant portal hypertension by HVPG more than 10 (Zaman et al, 1999; Berzigotti et al, 2013).

In the current study, no significant difference was detected between studied groups regarding alanine transaminase values. Other studies did not elicit association between liver enzymes values and clinically significant portal hypertension detected by presence of esophageal varices (Jeon et al, 2006;
Sharma et al, 2007; Fagundes et al, 2008), but, one study established a predictive model for detecting patients with clinically significant portal hypertension using alanine transaminase, albumin and international normalized ratio (Berzigotti et al, 2008).

The present patients with clinically significant portal hypertension (CSPH) had statistical high creatinine values than the others (Woitas et al, 1997; Rendón Unceta et al, 2001) but disagreed by others (Zaman et al, 1999; Berzigotti et al, 2008; Abuel Makarem et al, 2011) which found that portal hypertension in patients with cirrhosis was either compensated or not. Alpha fetoproteinwas significantly higher in $\mathrm{CSPH}$ patients that agreed with Ripoll et al. (2009), who found that portal hypertension was an independent predictor of $\mathrm{HCC}$ development in patients with compensated cirrhosis due to structural abnormalities, fibrogenesis and neoangiogenesis processes. Significant differences were between groups as to presence of collaterals and longest axis diameter of spleen on ultrasound imaging in CSPH patients that agreed with authors (Sarangapani et al, 2010; Berzigotti et al, 2011; Cherian et al, 2011; Esmat et al, 2011). Also, no statistical difference was found between groups as to number, extension or size of largest hepatic focal lesion; as patients were selected with child A compensated cirrhosis with- 
out vascular invasion or extrahepatic spread. Gastroesophageal varices was commonest in patients with CSPH with highly significant difference that agreed with others (GarciaTsao et al, 1985; Groszmann et al, 1990). Portal hypertensive gastropathy significantly higher in same patients agreed with others (Kim et al, 2010; Kumar et al, 2010).

In this study, Giannini index was significantly lower in patients with CSPH with high statistical significant difference which is consistent with other studies (Giannini et al, 2003; 2006; Sharma et al, 2007; Agha et al, 2009; Barrera et al, 2009; Sarangapani et al, 2010; Abu El Makarem et al, 2011; Ying et al, 2012). This went with other studies (Iwao et al, 1997; Plestina et al, 2005; Jeon et al, 2006; Tarzamni et al, 2008; Sarangapani et al, 2010; Cherian et al, 2011; Hong et al, 2011), the present study showed significant statistical differences between groups as to portal vein diameter, portal vein cross sectional area, portal vein mean flow velocity and portal vein congestion index. Others (Zaman et al, 1999; Choi et al, 2003) found no relation between Doppler parameters and HVPG due to significant variability in portosystemic collateral patterns (Merkel et al, 1998). The significant differences were between groups as to splenic vein diameter, splenic vein cross sectional area, splenic vein mean flow velocity and splenic vein congestion index agreed with others (Rodriquez et al, 1999; El Zeiny et al, 2002; Kayacetin et al, 2004), but differed due to lower sample sizes (De Bem et al, 2006) or due to liver disease with bleeding varices (Choi et al, 2003).

In the present study, HARI, SARI \& RARI were highly significantly increased in CSPH patients compared to those without, who agreed with other studies (Piscaglia et al, 1997; Colli et al, 2001; Berzigotti et al, 2006; 20; Vizzutti et al, 2007; Zhang et al, 2007; Tarzamni et al, 2008); nut disagreed with Choi et al. (2003). Also, the present
PHI were significantly higher in patients with portal hypertension while MLVI was significantly lower which agreed with others (Iwao et al, 1997; Amer et al, 2001; Piscaglia et al, 2001; Haktanir et al, 2005; Zhang et al, 2007; Tarzamni et al, 2008).

In the present study, loss of triphasic hepatic venous waveform was commonest in patients with $\mathrm{CSPH}$, which agreed with two studies (Kim et al, 2007; Joseph et al, 2011), but disagreed with one study (Bhutto et al, 2012). Also, as all significant variables in univariate analysis could not be included in same regression model, different models were generated that gave highest likelihood ratio and good fitness. Portal vein diameter more than or equal to $1.3 \mathrm{~cm}$, mono or biphasic pattern of flow in hepatic veins and Giannini index below or equal to 909 (Giannini et al, 2003) were independent risk factors for clinically significant portal hypertension by HVPG more than $10 \mathrm{mmHg}$. Performance of prediction model was displayed by ROC curve. AUC was 0.969 (0.938-1). The model gave a good discrimination between patients with HVPG more than 10 and those with lower HVPG.

The predictive models diagnoses $\mathrm{CSPH}$ in cirrhotic patients based on liver stiffness, platelet count and spleen size (Berzigotti et al, 2013), bilirubin (Park et al, 2009), palpable spleen, low platelet count, spleen size $>$ $13.8 \mathrm{~mm}$, portal vein $>13 \mathrm{~mm}$ and splenic vein $>11.5 \mathrm{~mm}$ (Sarangapani et al, 2010), palpable spleen and thrombocytopenia (Sharma et al, 2007), prothrombin time, portal vein diameter and splenic width (Hong et al, 2011), low platelet count, Child-Pugh class $\mathrm{B} / \mathrm{C}$, spleen diameter and platelet spleen diameter ratio 909 (Cherian et al, 2011) or $\mathrm{PH}$ index and splenic diameter (Tarzamni et al, 2008) but none studied such models in HCC patients. Bilirubin level and prothrombin time showed no statistical different, as patients with Child class A compensated cirrhosis, and $\mathrm{PH}$ index significantly correlated 
with HVPG gave accepted likelihood ratio or fitness.

\section{Conclusion}

Portal vein diameter $\geq 1.3 \mathrm{~cm}$, mono or biphasic pattern of flow in hepatic veins and Giannini index $\leq 909$ were 3 parameters in used model for non-invasive prediction of portal hypertension. This model in other patients' groups; cirrhotic without HCC, decompensated cirrhotic patients and cirrhotic patients due to etiologies other than $\mathrm{HCV}$ are strongly recommended.

The authors have no conflict of interest.

\section{References}

Abuel Makarem, M, Shatat, M, Shaker, Y, Abdel Aleem, A, Elsherif, A, et al, 2011: Platelet count/bipolar spleen diameter ratio for the prediction of esophageal varices: The special Egyptian situation: Noninvasive prediction of esophageal varices. Hepat Mon. 11:278-84.

Agha, A, Anwar, E, Bashir, K, Savarino, V, Giannini, E, 2009: External validation of the platelet count/spleen diameter ratio for the diagnosis of esophageal varices in hepatitis $\mathrm{C}$ virusrelated cirrhosis. Dig. Dis. Sci. 54:654-60.

Amer, G, Gazareen, S, Waked J, 2001: Clinical and ultrasonographic prediction of oesophageal varices in liver cirrhosis. Minoufia Med. J. 14, 1:105-12.

Baik, S, Kim, J, Kim, H, Kwon, S, Kim, Y, et al, 2006: Recent variceal bleeding: DUS hepatic vein waveform in assessment of severity of portal hypertension and vasoactive drug response. Radiology 240:574-80.

Barrera, F, Riquelme, A, Soza, A, Contreras, A, Barrios, G, et al, 2009: Platelet count/spleen diameter ratio for non-invasive prediction of high risk esophageal varices in cirrhotic patients. Ann. Hepatol. 8:325-30.

Berzigotti, A, Piscaglia, F. 2011: Ultrasound in portal hypertension. Part 1. Ultraschall. Med. 32: 548-68.

Berzigotti, A, Casadei, A, Magalotti, D, Castaldini, N, Losinno, F, et al, 2006: Renovascular impedance correlates with portal pressure in cirrhotic patients. Radiology 240:581-86.

Berzigotti, A, Gilabert, R, Abraldes, J, Nicolau, C, et al, 2008: Noninvasive prediction of clinically significant portal hypertension \& eso- phageal varices in patients with compensated liver cirrhosis. Am. J. Gastroenterol. 103:1159-67. Berzigotti, A, Seijo, S, Arena, U, Abraldes, J, Vizzutti, F, et al, 2013: Elastography, spleen size, and platelet count identify portal hypertension in patients with compensated cirrhosis. Gastroenterology 144:102-11.

Bhutto, A, Abbasi, A, Butt, N, Khan, A, Munir, S, 2012: Hepatic vein waveform in liver cirrhosis: correlation with child's class and size of varices. J. Pak. Med. Assoc. 62:794-7.

Bolognesi, M, Sacerdoti, D, Merkel, C, Bombonato, G, Gatta, A, 2001: Noninvasive grading of the severity of portal hypertension in cirrhotic patients by echo-color-Doppler. Ultrasound Med. Biol. 27:901-7.

Bolondi, L, Gandolfi, L, Arienti, V, Caletti, G, Corcioni, E, et al, 1982: Ultrasonography in the diagnosis of portal hypertension: diminished response of portal vessels to respiration. Radiology 142:167-72.

Bruix, J, Sherman, M, 2005: Management of hepatocellular carcinoma. Hepatol. 42:1208- 36.

Cherian, J, Deepak, N, Ponnusamy, R, Somasundaram, A, Jayanthi, V, 2011: Non-invasive predictors of esophageal varices. Saudi J. Gastroenterol. 17: 64-8.

Choi, Y, Baik, S, Park, D, Kim, M, Kim, H, et al, 2003: Comparison of Doppler ultrasonography and the hepatic venous pressure gradient in assessing portal hypertension in liver cirrhosis. J. Gastroenterol. Hepatol. 18:424-9.

Colli, A, Fraquelli, M, Pometta, R, Cocciolo, $M$, Visentin, S, et al, 2001: Renovascular impedance and esophageal varices in patients with Child-Pugh class A cirrhosis. Radiology 219: 712-15.

Cottone, M, D'Amico, G, Maringhini, A, et al, 1986: Predictive value of ultrasonography in the screening of non-ascitic cirrhotic patients with large varices. J Ultrasound Med. 5:189-92.

De Bem, R, Lora, F, de Souza, R, Trippia, M, Amarante, H, et al, 2006: Correlation of Doppler ultrasound of portal system with endoscopic changes caused by portal hypertension in cirrhotic patients. Arch. Gastroenterol. 43:178-83

De Franchis, R, Eisen, G, Laine, L, Fernandez, I, et al, 2008: Esophageal capsule endoscopy for screening and surveillance of esophageal 
varices in patients with portal hypertension. Hepatol. 47:1595-603.

El Zeiny, M, Taha, R, Ramadan, M, 2002: Evaluation of the haemodynamic changes in the portal and splenic veins by color Doppler sonography in patients with chronic liver diseases. Sci. J. Az. Med. Fac. (Girls). 23, 1:591-602.

El-Zayadi, A, Badran, H, Shawky, S, Emara, S, El-Bareedy, A, et al, 2010: Effect of surveillance for hepatocellular carcinoma on tumor staging and treatment decisions in Egyptian patients. Hepatol. Int. 4:500-6.

Esmat, S, Omran, D, 2011: Study of noninvasive predictors of portal hypertension in liver cirrhotic Egyptian patients. J. Am. Sci. 7:962-8.

Fagundes, D, Ferreira, A, Roquete, M, Penna, F, Goulart, E, et al, 2008: Clinical and laboratory predictors of esophageal varices in children $\&$ adolescents with portal hypertension syndrome. J. Pediatr. Gastroenterol. Nutr. 46:178-83.

Garcia-Tsao, G, Groszmann, R, Fisher, R, Conn, H, Atterbury, C, et al, 1985: Portal pressure, presence of gastroesophageal varices and variceal bleeding. Hepatol. 5:419-24.

Giannini, E, Botta, F, Borro, P, Risso, D, Tomagnoli, $P$, et al, 2003: Platelet count/spleen diameter ratio: proposal and validation of a noninvasive parameter to predict the presence of oesophageal varices in patients with liver cirrhosis. Gut 52:1200-5.

Giannini, E, Zaman, A, Kreil, A, Floreani, A, Dulbecco, $P$, et al, 2006: Platelet count/spleen diameter ratio for the noninvasive diagnosis of esophageal varices: results of a multicenter, prospective, validation study. Am. J. Gastroenterol. 101:2511-19.

Groszmann, R, Bosch, J, Grace, N, Conn, H, Garcia-Tsao, O, et al, 1990: Hemodynamic events in a prospective randomized trial of propranolol versus placebo in the prevention of a first variceal hemorrhage. Gastroenterology 99: 1401-7.

Haktanir, A, Cihan, B, Celenk, C, Cihan, S, 2005: Value of Doppler sonography in assessing the progression of chronic viral hepatitis and in the diagnosis and grading of cirrhosis. J. Ultrasound Med. 24:311-21.

Hong, W, Dong, L, Jiang, Z, Jiang, Z, et al, 2011: Prediction of large esophageal varices in cirrhotic patients using classification \& regress- on tree analysis. Clinics (Sao Paulo) 66: 119-24. Iwao, T, Toyonaga, A, Oho, K, Tayama, C, Masumoto, H, et al, 1997: Value of Doppler ultrasound parameters of portal vein and hepatic artery in the diagnosis of cirrhosis and portal hypertension. Am. J. Gastroenterol. 92:1012-17. Jeon, S, Cho, C, Tak, W, Ryeom, H, Kweon, Y, et al, 2006: The value of Doppler-ultrasonography and laboratory tests as non-invasive predictors of the presence of esophageal varices in patients with chronic liver disease. Korean J. Gastroenterol. 48:180-7.

Joseph, T, Madhavan, M, Devadas, K, et al, 2011: Doppler assessment of hepatic venous waves for predicting large varic es in cirrhotic patients. Saudi J. Gastroenterol. 17:36-9.

Kayacetin, E, Efe, D, Dogan, C, 2004: Portal and splenic hemodynamics in cirrhotic patients: relationship between esophageal variceal bleeding and the severity of hepatic failure. J. Gastroenterol. 39:661-7.

Kim, M, Baik, S, Park, D, Lim, D, Kim, J, et al, 2007: Damping index of Doppler hepatic vein waveform to assess severity of portal hypertension and response to propranolol in liver cirrhosis: a prospective nonrandomized study. Liver Int. 27:1103-10.

Kim, M, Choi, H, Baik, S, Yea, C, Won, C, et al, 2010: Portal hypertensive gastropathy: correlation with portal hypertension and prognosis in cirrhosis. Dig. Dis. Sci. 55:3561-7.

Kumar, A, Mishra, S, Sharma, P, Sharma, B, Sarin S, 2010: Clinical, laboratory, and hemodynamic parameters in portal hypertensive gastropathy: a study of 254 cirrhotics. J. Clin. Gastroenterol. 44:294-300.

Llovet, J, Ducreux, M, Lencioni, R, Di Bisceglie, A, Galle, $P$, et al, 2012: EASL-EORTC clinical practice guidelines: Management of hepatocellular carcinoma. J. Hepatol. 56, 4:908-43.

Llovet, J, Ricci, S, Mazzaferro, V, Hilgard, P, et al, 2008: Sorafenib in advanced hepatocellular carcinoma. N. Engl. J. Med. 359:378-90.

Merkel, C, Sacerdoti, D, Bolognesi, M, Bombonato, G, Gatta, A, 1998: Doppler sonography and hepatic vein catheterization in portal hypertension: assessment of agreement in evaluating severity and response to treatment. J. Hepatol. 28:622-30.

Moriyasu, F, Nishida, O, Ban, N, Nakamura, T, 
Sakai, M, et al, 1986: "Congestion index" of the portal vein. Am. J. Roentgenol. 146:735-39.

Ozaki, C, Anderson, J, Lieberman, R, Rikk-ers, L, 1988: Duplex ultrasonography as a noninvasive technique for assessing portal hemodynamics. Am. J. Surg. 155:70-3.

Parikh, S, 2009: Hepatic venous pressure gradient: worth another look? Dig. Dis. Sci. 54:1178-83. Park, S, Park, T, Kim, Y, Kim, S, Baik, G, et al, 2009: Non-invasive model predicting clinicallysignificant portal hypertension in patients with advanced fibrosis. J. Gastroenterol. Hepatol. 24:1289-93.

Piscaglia, F, Donati, G, Serra, C, Muratori, R, Solmi, L, et al, 2001: Value of splanchnic Doppler ultrasound in the diagnosis of portal hypertension. Ultrasound Med. Biol. 27: 893-99.

Piscaglia, F, Gaiani, S, Zironi, G, Gramantieri, L, Casali, A, et al, 1997: Intra- and extra-hepatic arterial resistances in chronic hepatitis and liver cirrhosis. Ultrasound Med. Biol. 23: 675-82.

Plestina, S, Pulanić, R, Kralik, M, Plestina, S, Samarziia, M, 2005: Color Doppler ultra-sonography is reliable in assessing the risk of esophageal variceal bleeding in patients with liver cirrhosis. Wien Klin. Wochenschr. 117:711-17.

Pozniak, M, 2002: Doppler ultrasound of liver. In: Clinical Doppler Ultrasound. Churchill Livigstone, London, Edinburgh, NY, Philadelphia.

Qamar, A, Grace, N, Groszmann, R, GarciaTsao, G, Bosch, J, et al, 2008: Platelet count is not a predictor of the presence or development of gastroesophageal varices in cirrhosis. Hepatol.47:153-9.

Rendón-Unceta, P, Rodríguez, M, Mariscal, P, Cabrera, M, Martinez, SM, et al, 2001: Renal Doppler ultrasonography and its relationship with the renal function in patients with liver cirrhosis. Med Clin (Barc) 116:561-4.

Ripoll, C, Groszmann, R, Garcia-Tsao, G, Bosch, J, Grace, $\mathbf{N}$ et al, 2009: Hepatic venous pressure gradient predicts development of hepatocellular carcinoma independently of severity of cirrhosis. J. Hepatol. 50:923-8.

Rodriquez, A, Martin, A, Oterino, J, Blanco, I, et al, 1999: Renal function in compensated he-patic cirrhosis: effects of an amino acid infusion and relationship with nitric acid. Dig. Dis. 17: 235-40.

Sacerdoti, D, Merkel, C, Gatta, A, 1991: Importance of the 1 month effect of nadolol on portal pressure in predicting failure of prevention of rebleeding in cirrhosis. J. Hepatol. 12:124-5.
Sarangapani, A, Shanmugam, C, Kalyanasundaram, M, Rangachari, B, Thangayelu, P, et al, 2010: Noninvasive prediction of large esophageal varices in chronic liver disease patients. Saudi J. Gastroenterol. 16:38-42.

Schneider, A, Kalk, J, Klein, C, 1999: Hepatic arterial pulsatility index in cirrhosis: correlation with portal pressure. J. Hepatol. 30: 876-81.

Sharma, S, Aggarwal, R, 2007: Prediction of large esophageal varices in patients with cirrhosis of the liver using clinical, laboratory and imaging parameters. J. Gastroenterol. Hepatol. 22: 1909-15. Taourel, P, Blanc, P, Dauzat, $M$, Chabre, $M$, Pradel, J, et al, 1998: Doppler study of mesenteric, hepatic, and portal circulation in alcoholic cirrhosis: relationship between quantitative Doppler measurements and severity of portal hypertension and hepatic failure. Hepatol. 28:932-6.

Tarzamni, M, Somi, M, Farhang, S, Jalily- and, M. 2008: Portal hemodynamics as predictors of high risk esophageal varices in cirrhotic patients. World J. Gastroenterol. 14:1898-902. van Leeuwen, M, 1990: Doppler ultrasound in evaluation of portal hypertension. Clin. Diagn. Ultrasound. 26:53-76.

Vizzutti, F, Romanelli, R, Arena, U, Rega, L, Brogi, M, et al, 2007: ADMA correlates with portal pressure in patients with compensated cirrhosis. Euro J. Clin. Invest. 37:509-15.

Woitas, R, Heller, J, Stoffel-Wagner, B, Spengler, U, Sauerbruch, T, 1997: Renal functional reserve and nitric oxide in patients with compensated liver cirrhosis. Hepatol. 26: 858-64.

Ying, L, Lin, X, Xie, Z, Hu, Y, Shi, K, 2012: Performance of platelet count/spleen diameter ratio for diagnosis of esophageal varices in cirrhosis: a meta-analysis. Dig Dis Sci. 57:1672-81.

Zaman, A, Hapke, R, Flora, K, Rosen, H, Benner, K, 1999: Factors predicting the presence of esophageal or gastric varices in patients with advanced liver disease. Am. J. Gastroenterol. 94: 3292-6.

Zhang, L, Duan, Y, Li, J, Yin, J, 2007: Hemodynamic features of Doppler ultrasonography in patients with portal hypertension: intraoperative direct measurement of portal pressure in portal venous system. J. Ultrasound Med. 26:1689-96.

Zoli, M, Iervese, T, Merkel, C, Bianchi, G, Magalotti, D, et al, 1993: Prognostic significance of portal hemodynamics in patients with compensated cirrhosis. J. Hepatol. 17:56-61. 